\title{
The Oil Sands Pit Lake Model - Sediment Diagenesis Module
}

\author{
S. Prakash a , J.A. Vandenberg ${ }^{b}$, and E. Buchak ${ }^{\text {a }}$ \\ ${ }^{a}$ ERM Inc. ${ }^{b}$ Golder Associates Ltd. \\ Email: Jerry_Vandenberg@,Golder.com
}

\begin{abstract}
In the Athabasca Oil Sands Region of Canada, bitumen is close enough to the surface and sufficiently concentrated to be recovered using conventional surface mining and chemical extraction. At the end of mining operations, oil sands mining operators have proposed to use pit lakes as closure waterbodies, and many of these pit lakes will contain water-capped tailings. The tailings pore water will contain various amounts of labile and refractory organic compounds, nutrients, trace metals and ion concentrations that ultimately will be released to the water cap as the tailings consolidate.

In addition to advective release of constituents, chemical reactions within the tailings will result in changes to the redox state, speciation and phase of several chemicals. To predict the fate of various constituents in oil sands tailings, a sediment diagenesis module has been developed that is coupled with CE-QUAL-W2. The module includes several physical and chemical processes, such as tailings consolidation, coupled with lake bed deepening and pore water release; biogenic gas production (build up and release of methane, hydrogen sulphide and ammonia); physical release of bubbles through water column; unconsolidated sediment resuspension during bubble ebullition; dynamic oxygen consumption at lake bed (from sediments) and in water column (from bubbles); salt rejection during ice formation.
\end{abstract}

This paper presents the model framework used to develop the Oil Sands Pit Lake Model sediment diagenesis module, including the basis for module algorithms, stage of development and potential uses for the model.

Keywords: Pit lakes, mature fine tailings, methane, diagenesis, gas release, bubbling, bed consolidation, oil sands 


\section{INTRODUCTION}

This paper describes the Oil Sands Pit Lake Model (OSPLM) that was developed to model sediment and water quality in oil sands pit lakes. The OSPLM is a sediment diagenesis module that can be used to predict the fate and transformations of substances in water-capped tailings. It is designed to link dynamically with the standard version of CE-QUAL-W2 (W2). It can be applied to pit lakes with or without tailings.

The work was funded by the Cumulative Environmental Management Association (CEMA), a multistakeholder organization that provides recommendations to regulators on managing the regional environmental effects of oil sands development. The model was submitted to CEMA as an open-source project. The model code, as well as a comprehensive model report that describes the formulae for all processes, will be available on the CEMA website (http://cemaonline.ca/) once the model is made final, likely near the end of 2011.

\subsection{Background}

The oil sands of Alberta, Canada contain approximately 170 billion barrels of proven oil reserves. In the Athabasca Oil Sands Region, north of Fort McMurray, the bitumen is close enough to the surface to be mined using conventional mining techniques. Similar to mining operations in other resource industries (e.g., coal, metals and diamonds) oil sands mines will use pit lakes as part of their closure and reclamation strategy. Approximately 30 pit lakes will be created as part of approved and proposed oil sands mines in Alberta. In about half of these pit lakes, Mature Fine Tailings (MFT) will be placed in the pit before the pit is flooded with fresh water to create a lake. MFT is a mixture of fine clay materials that settle very slowly and release organic compounds with associated toxicity (Mikula et al. 1996), and therefore pose challenges to reclamation. As MFT consolidates, water is released to the overlying water column, which must have a sufficient volume and residence time to assimilate and degrade these residual compounds.

As part of an application for regulatory approval of an oil sands mine, pit lakes are assessed in an environmental impact assessment, which predicts water quality in each pit lake and in receiving watercourses. While these assessments incorporate the effects of water released from MFT using conservative assumptions regarding the quality of MFT release waters, there are currently no mechanistic models available to (1) compute the relevant processes that occur within the MFT, (2) simulate the formation and release of gas bubbles and (3) simulate the interaction of gases within bubbles with constituents in the water column.

\subsection{Present Scope of Work}

This paper describes the present state of development of the OSPLM. The present focus is to incorporate processes relevant to MFT and the overlying water column. These processes include chemical reactions within MFT that may result in the release of aqueous and gaseous compounds into the water column, leading to changes in pit lake water quality. The model simulates the anaerobic decay of these compounds and production of gases such as methane, which could alter the physiochemical nature of the pit lake water column. Processes included in the model are described more fully in Section 2.2.

Development of the OSPLM is a stepwise, research-based modelling exercise. At the time of this paper submission, the model framework and algorithms had been developed and made functional. Subsequently, model formulations will be validated, model limitations will be analyzed and addressed, and the model will be refined to be used in full-scale operations. As such, it is recognized that the present stage of model development is "experimental", and future refinements of the model are anticipated.

\section{OIL SANDS PIT LAKE MODEL}

\subsection{Model Platform}

The freely-distributed W2 Version 3.6 (Cole and Wells 2008) forms the basis of the OSPLM. The default version of W2 is distributed by the Water Quality Research Group at Portland State University. This sediment diagenesis module was written in FORTRAN, and was added to the W2 code to create a single, fully-coupled model. Additional processes relevant to the OSPLM were programmatically added in different modules. These modules were written in separate FORTRAN files to keep the existing W2 code in its original form. 


\subsection{Pit Lake Representation}

The pit lakes in OSPLM are represented by incorporating the MFT bed, additional processes within the water column and at the water surface. The key components of the pit lakes that have been included in OSPLM are shown in Figure 1. The following sections describe these processes and components individually.

\section{Tailings Consolidation, Lake Deepening and Porewater Release}

Tailings placed in the pit lakes will consolidate over time, releasing porewater into the overlying water column. The overall effect is that the pit lakes will deepen over time from their original bed elevations. The time for complete settling of MFT has been estimated at 125 to 150 years (Eckert et al. 1996), although methanogenesis may reduce this settling time considerably (Fedorak et al. 2003, Foght et al. 2010).

W2 is a traditional, fixed-grid model in which the bathymetric surface is static. In such a model, the initial bathymetric surface is used to create a grid on which hydrodynamic and transport computations are performed. The waterbody bathymetry and, consequently, the gridded representation of the bathymetric surface, are fixed throughout a simulation. To include the process of tailings consolidation and the resulting lake deepening, modifications to the W2 code were made to include a time-varying lake bottom. As modified, the model grid is developed from the initial lake bathymetry. During a simulation, the tailings consolidation is calculated based on user-defined rates that can vary spatially. During consolidation, tailings bed porosity and total pore volume are calculated based on the consolidation rate. A volume of porewater, equal to the change in total pore volume since the previous timestep, is expressed from the tailings. This amount of porewater is released into the overlying water column along with porewater constituents. The porewater constituents may include the default chemicals, as well as generic constituents and generic Biochemical Oxygen Demand (BOD) groups. Generic constituents and BOD groups that are defined in the sediment compartment are transferred to the water column, where they link in with the standard W2 variables.

\section{Tailings Gas Production}

A sediment bed was incorporated into the existing W2 framework as a separate compartment. The sediment bed was tailored to MFT constituents, although the processes are applicable to other substrates. The sediment bed was represented by an upper and lower layer to represent variable oxic conditions. Production of gas during methanogenesis and other diagenesis processes within the sediment bed were incorporated based on generic formulations provided by DiToro (2001). These diagenesis processes are shown in Figure 2 . The upper layer, in contact with the water column, may be aerobic or anaerobic, depending on the dissolved oxygen concentration in the overlying water column and the oxygen demand exerted by the sediment bed. The thickness of the aerobic layer is calculated internally by the penetration of oxygen into the sediments. The presence of oxygen in the aerobic layer controls all oxidation processes in this layer. Even at its maximum thickness, the aerobic layer is an insignificant fraction of the total sediment bed in terms of volume. The lower layer is always anaerobic and is the predominant source of diagenetic fluxes.

The diagenesis process refers to the decay of organic matter within sediment that consists of particulate organic carbon (POC), particulate organic nitrogen (PON) and sulphate. Both PON and POC are further subdivided into different reaction classes: labile, refractory and inert. These different reaction classes are included as they proceed at different rates. The labile class represents rapidly decaying organic matter, the refractory class represents slow decaying organic matter and the inert class represents any fraction of PON or POC that does not participate in the diagenesis process. Inclusion of the inert class is required for the mass balance of the system. The diagenetic products from the anaerobic layer diffuse into the upper aerobic layer and eventually to the water column. Within the aerobic layer, the diagenetic products undergo oxidation that consumes diffused oxygen from the water column, thereby exerting sediment oxygen demand on the overlying water.

The rates of reactions applied in the diagenesis formulations are generally temperature dependent, and OSPLM makes use of this temperature-dependent relationship. Also, diagenesis products such as sulphide and ammonia can undergo ionization based on their ionization potential and water $\mathrm{pH}$. The ionization process occurring within the sediment bed is also included in the OSPLM. 


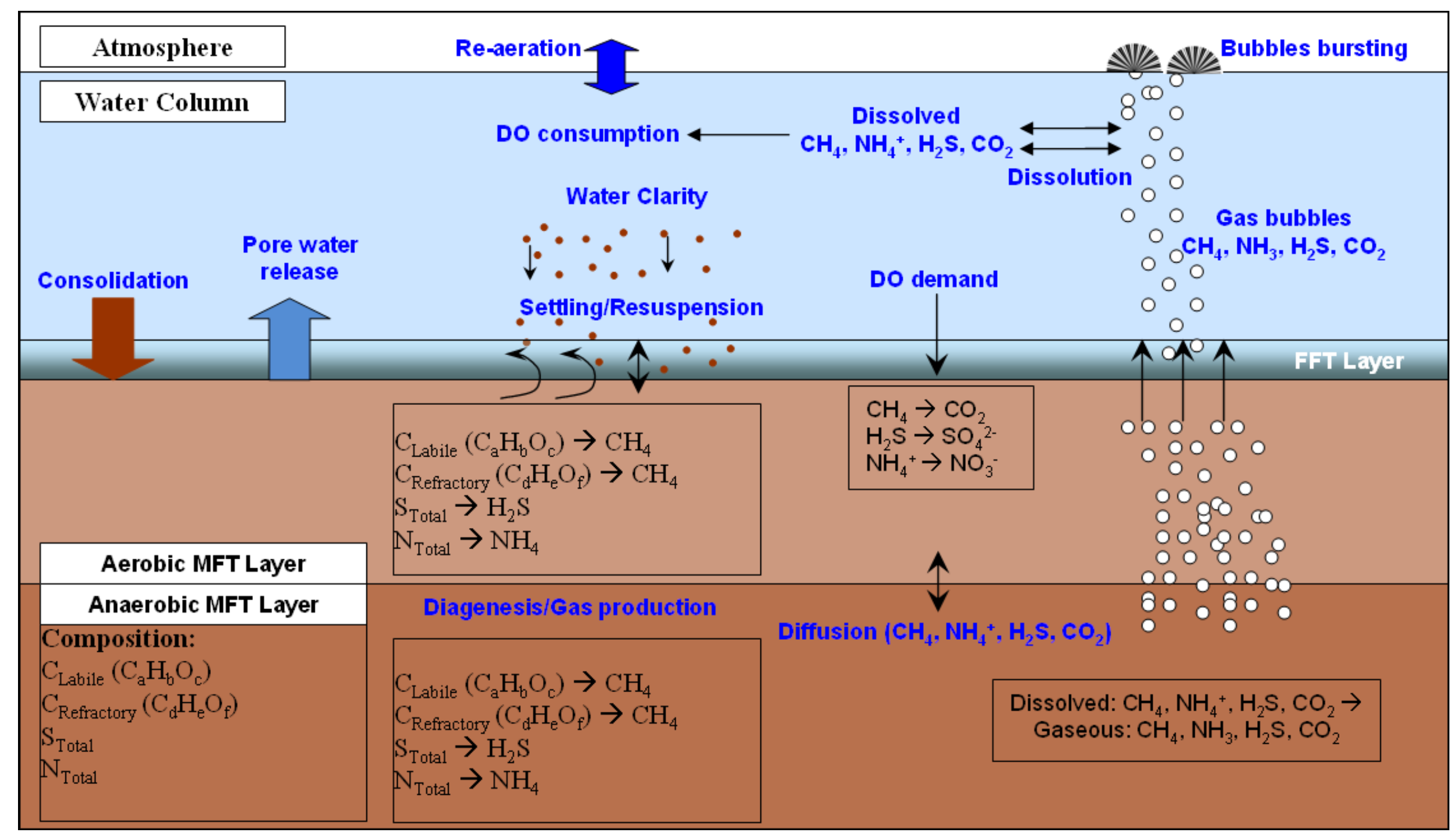

Figure 1: Conceptual Diagram of Processes Included in the Oil Sands Pit Lake Model 


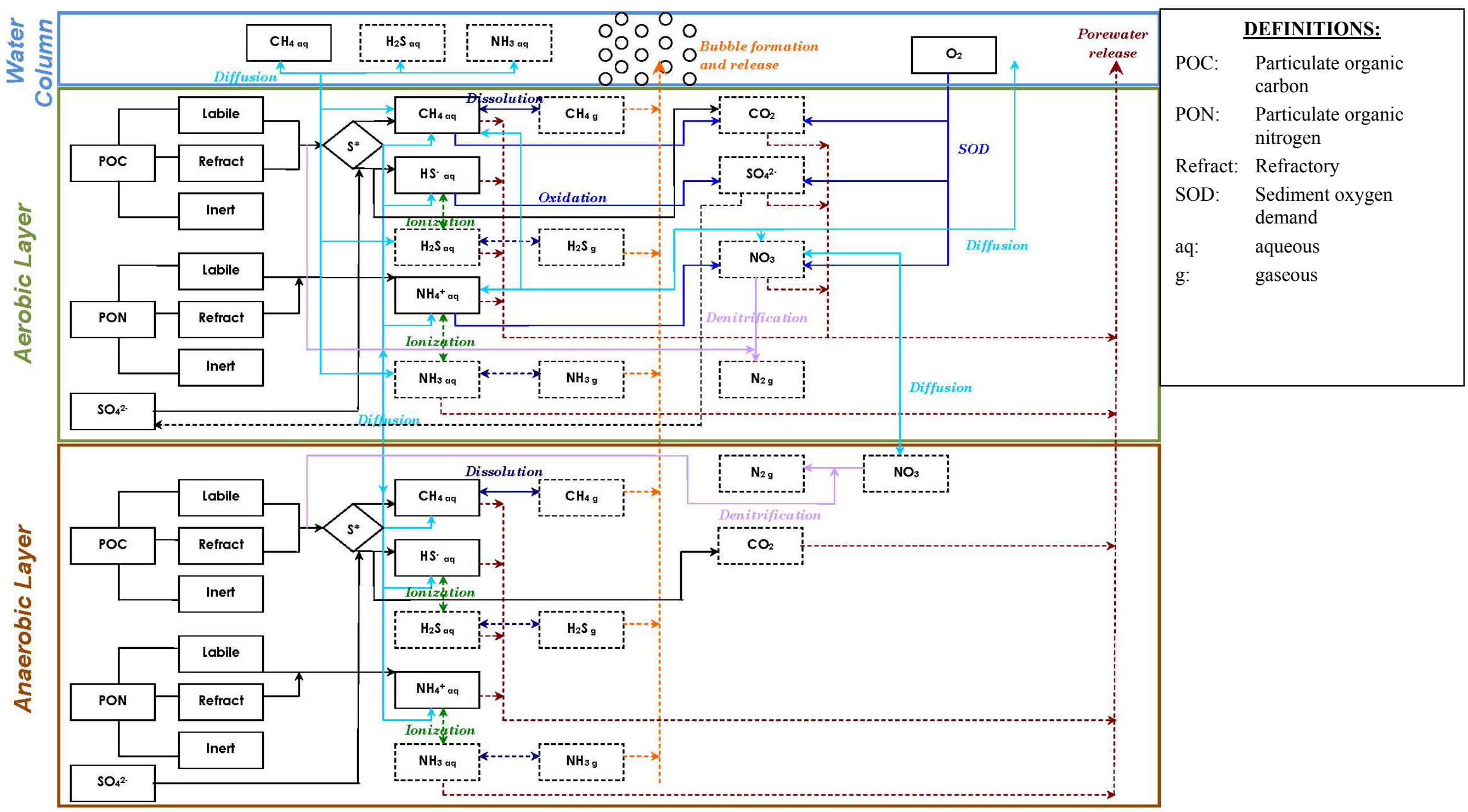

Figure 2: Diagenesis Framework 
Continuous production of dissolved gases $\left(\mathrm{H}_{2} \mathrm{~S}, \mathrm{CH}_{4}, \mathrm{CO}_{2}\right.$ and $\left.\mathrm{NH}_{3}\right)$ through diagenesis may result in supersaturation, at which point bubbles form. The relationship between the dissolved and gaseous (bubble) phase is described by Henry's Law. The solubility of each gas determines the amount of gas formed in the interstitial pores. In situ rates of bubble formation have not been measured in MFT, and thus OSPLM relies on bubble formation and growth relationships. The growth model adopted for OSPLM is based on the work of Boudreau et al. (2001a, 2001b). This model was chosen because it considers a distributed source of gas formation which is not normally included in other bubble growth models. This approach is important as the sediment bed continually produces gas through diagenesis. The nucleation kinetics are ignored in OSPLM by assuming that there are abundant nucleation sites and that the bubbles form without hindrance. Similarly, the rate of growth of bubbles in sediments is sufficiently slow that adsorption kinetics can be ignored. This assumption leaves only transport and mechanical controls to be considered.

\section{Bubbling to Surface}

The bubbles formed within the sediment bed are released into the water column once the gas pressure exceeds the bed strength. The physics of bubble escape from sediments has not been studied in detail in oil sands pit lakes. However, multi-phase systems have been studied in the context of contaminated sites, methane hydrate recovery and greenhouse gas accounting. The formation of gas bubbles in sediments and release to the overlying water column is described by van Kesteren and van Kessel (2002) in their work relating to harbour sludge. Briefly, gases $\left(\mathrm{CH}_{4}\right.$ and $\left.\mathrm{CO}_{2}\right)$ are produced by methanogenesis, which increases the concentration of these gases in interstitial waters within the sediments. In fine sediments, advective and diffusive transport of gases from the interstitial waters is very slow. Therefore, additional gases being produced lead to higher dissolved gas concentrations up to the point of saturation (as determined by Henry's Law), at which point bubbles will form. Bubbles continue to grow until the upward force on the sediment exceeds the fracture energy, at which point the bubbles escape to the overlying water column.

Once the bubbles are released from the sediment bed, it is important to consider the turbulence that results from these bubbles. This turbulence is estimated by applying a simplified correction that accounts for bubbleinduced turbulence based on the turbulence viscosity (Hosokawa and Tomiyama 2010). The internallycalculated W2 turbulent viscosity is modified by applying a correction factor that is a function of bubble diameter and bubble rise velocity. Once the bubbles are in the water column, they rise due to the buoyancy forces acting on them. The bubbles exchange gases with the water column during their transit through the water column. Once the bubbles rise to the water surface, a burst factor releases these gases to the atmosphere. Henry's Law defines the exchange of gases between the bubbles and the water column.

\section{Non-algal Water Clarity}

The sediments in the sediment bed consisting of unconsolidated MFT can experience resuspension and resettling from the water column. Water clarity or turbidity is an indicator of the amount of these suspended sediments. Relationships between Total Suspended Solids (TSS) and turbidity can be developed based on site-specific data. TSS includes both suspended sediment and organic material in a water sample. The relationship between TSS and turbidity is usually considered to be linear on a natural logarithmic scale (Packman et al. 1999). A similar relationship was applied for the OSPLM.

\section{Fluid Fine Tails Layer}

In lakes that contain MFT, overlying the MFT bed is a gel-like layer of fine tailings that may act as a barrier between the MFT bed and the water column. This layer, termed the Fluid Fine Tails (FFT) layer, has been added to the OSPLM to account for phenomena observed in oil sands tailings ponds. The FFT layer is essentially an unconsolidated layer of very fine material suspended at the upper boundary between the MFTwater interface. The FFT layer was incorporated in the OSPLM by adding a highly dense water layer with TSS concentration in the range of $30 \%$ solids $\mathrm{w} / \mathrm{w}$.

\section{CONCLUSIONS AND RECOMMENDATIONS}

The development of OSPLM provides the first detailed model capable of estimating key oil sands pit lakes processes. The OSPLM has been developed such that the key process parameterizations are highly user definable. This allows for OSPLM application to a wide variety of pit lakes regardless of whether they contain MFT. Most of the processes included in the model framework can also be ignored by use of switches where such processes are not applicable. Recognizing that the OSPLM is in development stage, the following recommendations can be made as next steps:

- Obtain reasonable estimates, where available, for all applicable processes and characteristics (e.g., gas production rates, dissolved gas concentrations, dissolved constituent concentrations). The 
primary source of this information should be tailings ponds or experimental reclamation waterbodies on existing oil sands operations.

- Configure a preliminary model application based on available rates and coefficients to systematically test performance. Verify that the model responds as expected to changes in inputs. Identify any areas where reasonable rates cannot be predicted by the model, or where coefficients must be set outside of expected ranges to obtain reasonable results.

- If any processes cannot be replicated in the model using reasonable rates and coefficients, alternate formulae may need to be incorporated into the model.

- After the model framework has been validated, laboratory and field studies should be conducted to derive rates and coefficients where literature values cannot be obtained or where they are found to be inadequate for oil sands pit lakes.

\section{ACKNOWLEDGMENTS}

The authors would like to thank Cumulative Environmental Management Association (CEMA) for funding development of the Oil Sands Pit Lake Model.

\section{REFERENCES}

Boudreau, B.P., B.S. Gardiner and B.D. Johnson. 2001a. Rate of growth of isolated bubbles in sediments with a diagenetic source of methane. Limnol. Oceanogr. 46(3): 616-622.

Boudreau, B.P., B.S. Gardiner and B.D. Johnson. 2001b. Errata to Rate of growth of isolated bubbles in sediments with a diagenetic source of methane. Limnol. Oceanogr. 46(6):1578.

Cole, T.M. and S.A. Wells. 2008. CE-QUAL-W2: A Two-Dimensional, Laterally Averaged, Hydrodynamic and Water Quality Model, Version 3.6. Prepared for U.S. Army Corps of Engineers, Washington, DC 20314-1000.

DiToro, D.M. 2001. Sediment Flux Modeling. Wiley-Interscience. New York. 656pp.

Eckert, W.F., J.H. Masliyah, M.R. Gray and P.M. Fedorak. 1996. Prediction of sedimentation and consolidation of fine tails. AIChE Journal. 42(4):960-972.

Fedorak, P.M., D.L. Coy, M.J. Dudas, M.J. Simpson, A.J. Renneberg and M.D. MacKinnon. 2003. Microbially-mediated fugative gas production from oil sands tailings and increased tailings densification rates. Journal of Environmental Engineering and Science. 2:199-211.

Foght, J.M., D. Bressler, M. Cardenas, P.M. Fedorak, S. Guigard, R. Gupta and T. Siddique. 2010. Microbial activity influences pore water recovery from oil sands mature fine tailings. CONRAD Water Usage Workshop and Seminar. April 22, 2010. Edmonton, AB.

Hosokawa, S. and A. Tomiyama. 2010. Effects of Bubbles on Turbulent Flows in Vertical Channels. 7th International Conference on Multiphase Flow. ICMF 2010, May 30-June 4, 2010, Tampa, FL.

Mikula, R.J., K.L. Kasperski, R.D. Burns and M.D. MacKinnon. 1996. Nature and Fate of Oil Sands Fine Tailings. In Schramm, L.L., Suspensions: Fundamentals and Applications in the Petroleum Industry. American Chemical Society.

Packman, J.J., K.J., Comings, and D.B. Booth. 1999. Using turbidity to determine total suspended solids in urbanizing streams in the Puget Lowlands: in Confronting Uncertainty: Managing Change in Water Resources and the Environment, Canadian Water Resources Association annual meeting, Vancouver, BC, 27-29 October 1999, p. 158-165.

van Kesteren, W. and T. van Kessel. 2002. Gas bubble nucleation and growth in cohesive sediments. In: JC Winterwerp and C Kranenburg, Editors, Fine Sediment Dynamics in the Marine Environment. Proc Marine Science 5, Elsevier, Amsterdam. pp. 329-341. 